\title{
Investigating Environmental Impact Assessment (EIA) in Early Studies (Zero-Phase) to Prevent Delay in Operation of Construction Projects
}

\author{
Iraj Jalali ${ }^{\mathrm{a}^{*}}, \mathrm{~S}_{\text {. Mahammad Poorhashemi }}{ }^{\mathrm{b}}$, Alireza Mirjalili ${ }^{\mathrm{c}}$ \\ ${ }^{a}$ Department of Construction Engineering and Management, Yazd Branch, Islamic Azad University, Yazd, Iran. \\ ${ }^{b}$ Department of Physics, Yazd Branch, Islamic Azad University, Yazd, Iran. \\ ${ }^{c}$ Department of Construction Engineering and Management, Yazd Branch, Islamic Azad University, Yazd, Iran .
}

Received 16 October 2017; Accepted 19 January 2018

\begin{abstract}
Delay in project execution is one of the outmost problems that lead to delay to operation and subsequently, early structural erosion or financial supply disturbance, etc. Delay is fallen into several categories and each category has its own specific origin. However, in the present paper, environmental factors causing delay to projects are investigated. Delay to Construction Projects operation can be prevented by embedding environmental studies, namely environmental impact assessment (EIA) in initial studies. Given that environmental events cannot be predicted and we can only rely on statistic reports of previous periods, the effect of embedding such assessment in projects is so useful that every manger is convinced to make use of this assessment in study phase. The research results revealed that it is necessary to present EIA in initial studies to prevent delay to Construction Projects operation. In the following, given to the necessity of checklist, the quality of the designed checklist was investigated. Finally, the checklist was implemented and checked. In this study, each of the research questions was separately tested.
\end{abstract}

Keywords: Environmental Impact Assessment (EIA), Construction Project; Environmental Checklist; Delay.

\section{Introduction}

During constructing and operating Construction Projects, very detrimental unpredicted events may happen that lead to delay in construction or operation time. These factors may be harmful for environment or human. Identifying and assessing environmental risks during initial studies of a project can prevent the mentioned delays and increase their efficiency. Environmental impact assessment refers to identifying existing risks and classifying them to determine their dangers during construction and operation periods. These risks have various aspects in Construction Projects construction and they can be hardly identified. However, identifying and analyzing environment related risks or investigating and executing projects with EIA can prevent delay to Construction Projects during construction and particularly operation [1]. As probable delays in Construction Projects can be decreased using value engineering and risk management, using EIA can help achieve this goal [2].

Approving EIA regulation of large productive, service-providing and Construction Projects during the recent years and executing them has led to the obligation of possessing EIA reports for all projects. However, such reports unfortunately have found formality aspect and they are not so considered during designing and constructing projects. Considering this fact, presenting appropriate strategy to execute EIA report during various construction stages (design,

* Corresponding author: Irajjalali73@yahoo.com

\footnotetext{
dol http://dx.doi.org/10.28991/cej-030973

> This is an open access article under the CC-BY license (https://creativecommons.org/licenses/by/4.0/).

(C) Authors retain all copyrights.
} 
construction and operation) is necessary [3]. Therefore, it is highly important to present inspection checklists at the end of EIA reports and reviewing them in various stages of project execution and checking with EIA regulation to execute project or conditionally agree or disagree with design execution during early studies (zero phase) or presenting appropriate strategy to prevent serious damages to environment and its related issues during project execution. All these factors play a key role to prevent delay to Construction Projects operation.

\section{Literature Review}

The studies conducted on global status of environment during the two last decades indicate that in spite of the recent sensitivities regarding environment, destructive human effects not only have not been decreased but they have caused more serious problems such as atmosphere pollution, ozone layer depletion, greenhouse phenomenon, global warming, and various effects due to these phenomena [4]. Hence, considering environmental studies and conducting EIA studies in the stages of feasibility study, locating and before Construction Projects execution are regarded as one of the most effective managerial methods to decrease environmental effects and achieve sustainable development [5].

\subsection{Delay in Construction Projects}

Iranian studies on identifying the factors of delay in Construction Projects date back to the three last decades. Factors published in the reports before the revolution indicate that wrong estimation and design, increasing values and inappropriate execution methods are regarded as the main factors influencing delay in Construction Projects. Out of these factors, study and design problems and increasing values in this research have been also important [6]. Therefore, it can be concluded that design problems and increasing values are the main delay factors that have been institutionalized in Iran. Hodgson (1947) classified the factors of delay in Construction Projects of airport into structure and rules, incomplete study and design, improper estimation, weak contractor and his/her management, lack of timely supplying and allocating necessary credits, and lack of executing employer's commitments [7].

Chan and Kumaraswamy (2002) compared the causes of delay in projects of 11 countries and concluded that delay factors, particularly in developing countries, are identical. For example, in developing countries, improper design and estimation, weak project management and lack of materials are regarded as the most important delay factors. While, delay factors in developed countries such as USA and England are mainly justifiable delay factors including inclement weather and human resources performance [8].

In the Saudi Arabia, Oden and Battaineh (2002) introduced lack of credit, lack of paying contractors' statement, labor force related factors, and contracts related factors as the important delay factors. They also introduced design mistakes and changes, delay in paying contractors, financial problems of contractors, structural and bureaucracy problems in employer's organization [9].

In the Nigeria, Sonuga et al. (2002) introduced rules, inflation, design problems, corruption, and weak management as the main delay factors [10]. In Ghana, Frampog et al. (2003) considered design problems, financial problems, structure and rules, lack of human resources and materials as the important factors of delay in projects [11].

\subsection{Environmental Impact Assessment (EIA)}

The history of EIA and its legal importance dates back to the late 1960s (Diliman, 2005). Environmental policy rule of various organizations oblige them to investigate environmental effects before executing large projects. Accordingly, if there is the possibility of imposing unpleasant effects on environment by a project, the project is inevitable to provide EIA report before execution. For the first time, the process of providing EIA report got formal by enacting national environmental policy act (NEPA) in USA in 1969. Hence, after Stockholm conference in 1972, most of countries made themselves obliged to do EIA studies before executing projects [12].

EIA is an evaluative system that prevents reverse environmental effects due to development projects. EIA can be also a means to achieve sustainable development. The Principle 4 of Rio Treaty regarding sustainable development indicates that EIA should be a part of development process to achieve sustainable development and conserve environment. In all developed countries, EIA is executed for development projects and some organizations such as the World Bank consider EIA necessary to help development projects [13].

The purpose of EIA at the stages of project execution is to represent detriment environmental consequences in a stage of project planning process such that the negative effects are avoided or removed. In other words, EIA aims at specifying the level of predicted risks and efforts necessary to decrease or avoid risks as well as determining the way of compensating inevitable environmental damages [14].

Economic, social and environmental changes due to large projects execution is considered as development constituent. Although the purpose of development is to create positive changes and human welfare, development can finally cause some problems. Previously, shallow thoughts of decision makers regarding economic growth progress as a driving engine to increase welfare, effective factor of achieving development, without considering negative effects of 
these activities on environment and making sure about long-term benefits became the advent of sustainability concept. This concept can be accepted as a fundamental concept when the purpose of development is to increase welfare and justice to meet basic needs of today and future generations [15].

\section{Research Hypotheses}

Delay in Construction Projects operation and environmental impact assessment has been studied from various aspects; however, the relation between these two categories and presenting EIA in initial studies of Construction Projects to prevent delay to operation of completed projects seems necessary. Additionally, it is vital to attach EIA checklist during providing EIA report for each Construction Project. Generally, investigating the effect of environmental studies to prevent delay in Construction Projects operation can be regarded as the main objective of the present research such that such studies prevent delay in construction projects operation. However, objectives can partially be categorized as following:

- Investigating the role of time in Construction Projects and the consequences of delay in Construction Projects operation.

- Investigating the necessity of EIAs and its role to prevent delay in Construction Projects operation.

- Evaluating important environmental parameters.

In case of establishing such mechanism, all persons involved in construction process can be considered beneficiaries of the present paper. On the other hand, most of state organizations related to environmental activities such as environment organization, natural resources organization, planning and budget organization, road and urbanization ministry, etc. also have common objectives with this research.

\section{Methodology}

A typical construction process involves the use of various construction equipment and natural resources and generates many pollutants. As shown in Figure 1, the designer's responsibilities are to translate and develop the owner's specifications and prepare the design documents accordingly. Once the design of a building is completed, the major types of building materials are well defined in design documents. Thus, it is the designer, rather than the contractor, who should be responsible for the environmental impact of the manufacturing processes of those materials. The contractor, on the other hand, does not enter the process until a design is completed. The contractor usually prepares a pre-construction plan of a construction project, which specifies construction methods. Often, the construction methods involve equipment and ancillary materials that can potentially impact the environment. Because this study is focused on construction development, the EIA model for construction processes is limited to the analyzes of construction equipment and ancillary materials [16].

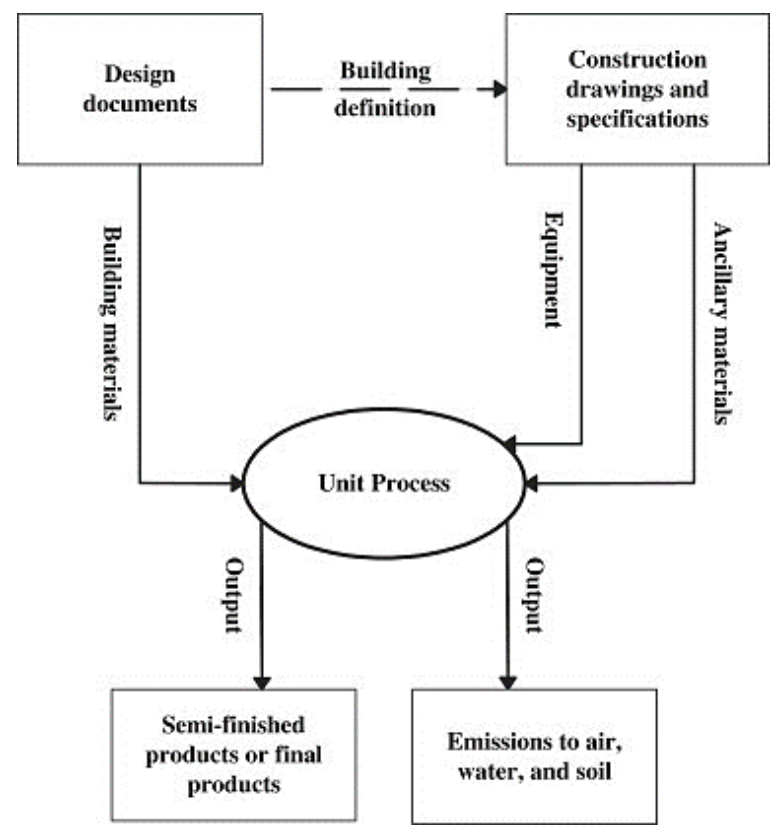

Figure 1. The scope of Environmental Impact Assessment (EIA) of construction projects development [16]

As shown in the Figure 2, in observation stage, initial information regarding environmental assessment and its role in time management and preventing delay to projects was firstly gathered using four methods. These four methods are as following: 


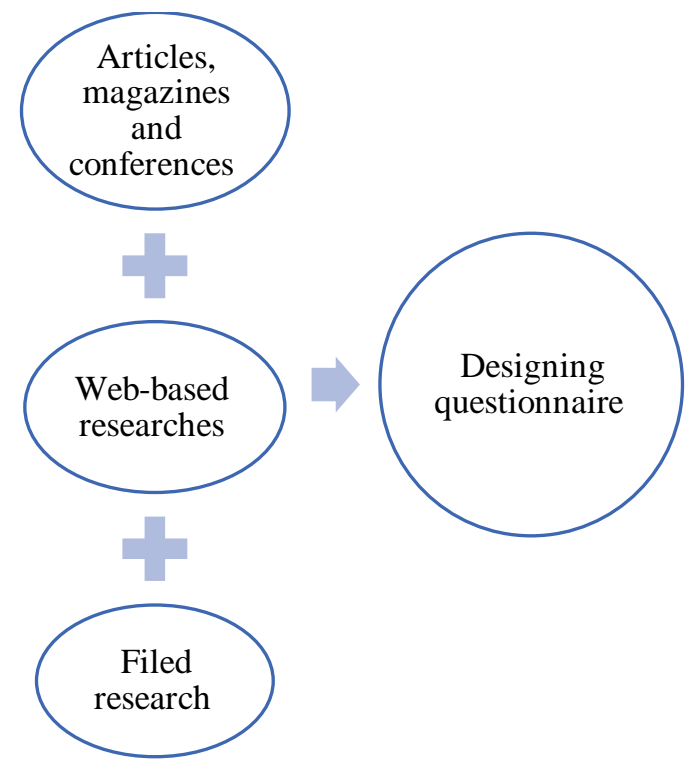

Figure 2. Information gathering stages

After this stage and receiving information about environmental assessment generalities as well as preventing delay in Construction Projects and integrating these two stages, it was decided about the research methodology. After investigating related literature, the effect of the considered assessment style on decision making and selecting time management system in projects or even in small operations (a part of project) was examined. Information gathering stages have been always established and in action and in effort stage, gathering adequate and required information, it was moved towards the predetermined objective.

\subsection{Procedure}

In the research methodology, to prevent delay in projects execution and operation in terms of environmental issues, a process should be institutionalized such that all projects are investigated based on a checklist before starting operations. In the present research, using previously reported studies as well as field studies and considering EIA reports provided by environmental organization and some consultant companies in executed or under execution projects, a series of questions about environmental assessment was designed to formulate a questionnaire. After formulating the questionnaire, by considering EIA report, it was classified based on the mentioned environments including physical (water, wind, and soil), biological (vegetation and wild life), economic, social, and cultural environments related to environmental pollution in assessment framework.

After gathering data and testing the questionnaire, the final checklist was sent to executive and consulting agents of several under execution and completed projects for comparison. The statistical population included employers, consultants and contractors who were professionally involved in Construction Projects.

\section{Data Analysis}

To analyze the gathered information, descriptive and inferential statistics were employed. In this regard, the research hypotheses were tested through SPSS Software. In the following, the results obtained by testing the hypotheses are presented.

In statistical analysis, there are two error levels ( 0.01 and 0.05$)$. The closer value to 0.05 indicates higher error and hypothesis is rejected and vice versa. The error level between 0.01 and 0.05 is also acceptable to confirm hypothesis; however, error level higher than 0.05 causes that hypothesis is rejected and vice versa.

\subsection{Testing Significance}

To select statistical test type, normality of data distribution was investigated. Using K-S test, it was found that the questionnaire scores were normal. Therefore, parametric tests were used to test the hypotheses. If a variable is not normal, parametric tests cannot be used and non-parametric tests are employed.

\subsection{Testing Data Normality (Kolmogorov-Smirnov)}

$\mathrm{H}_{0}$ : data are normal (data are from normal population).

$\mathrm{H}_{1}$ : data are not normal (data are not from normal population).

If significance level is higher than 0.05 , null hypothesis is confirmed and vice versa. 


\subsection{Investigating Data Distribution Normality}

Since significance value for entire the questionnaire is greater than 0.05 , it is concluded that the research variables have normal distribution.

Table 1. Investigating normal distribution of the research variables

\begin{tabular}{ccc}
\hline Variable & K-S test & Sig. \\
\hline Formulation and assessment & 0.965 & 0.309 \\
\hline
\end{tabular}

\subsection{Normality Cure of Data Distribution}

As shown in Figure 3, the research variable mean is at the middle of the distribution curve and has the highest frequency. As shown, those who obtained highest score are at the right side and those who obtained the lowest score are at the left side.

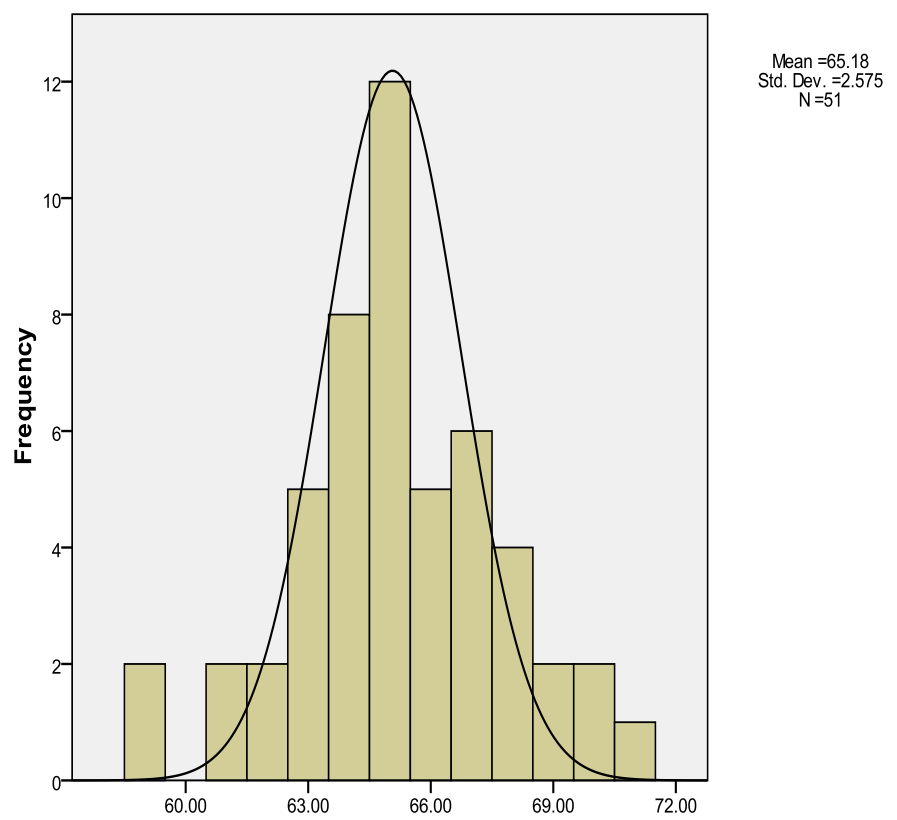

Figure 3. Normality distribution curve of the research variable (formulation and assessment)

According to Figure 4, the research variable mean is at the middle of the distribution curve and has the highest frequency. As shown, those who obtained highest score are at the right side and those who obtained the lowest score are at the left side.

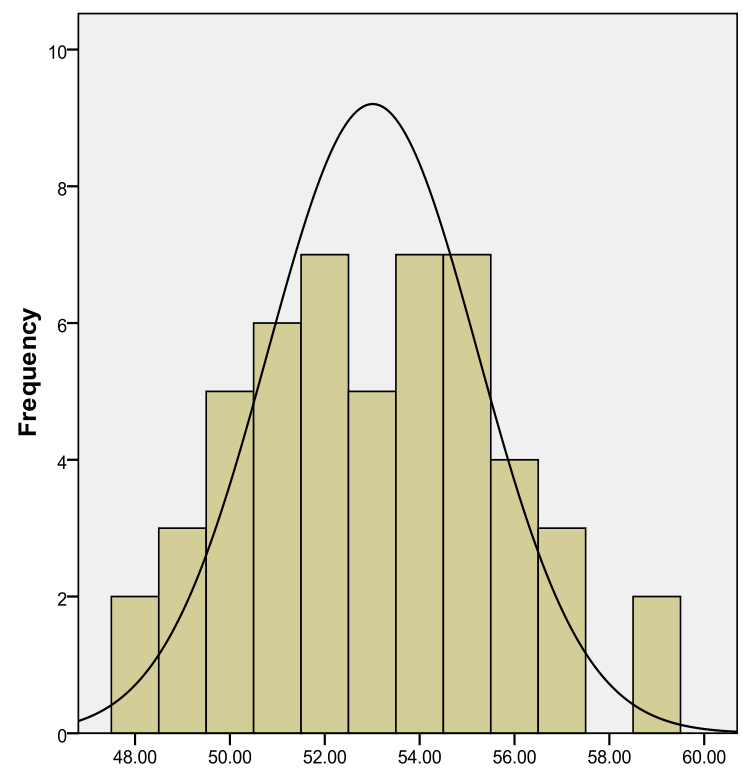

Mean $=53.02$
Std. Dev. $=2.702$
$\mathrm{~N}=51$

Figure 4. Normality distribution curve of the research variable (control and execution) 


\section{Describing Data and Research Hypotheses}

To better recognize studied population nature and research variables, before statistically analysing data, it is necessary to describe data. In the following, descriptive statistics of the study are presented:

Table 2. Descriptive statistics of the research variables

\begin{tabular}{|c|c|c|c|c|}
\hline Variable & Mean & Median & Standard deviation & Variance \\
\hline Inspection (control and execution) checklist & 53.0196 & 53.0000 & 2.70178 & 7.300 \\
\hline
\end{tabular}

- Is checklist is necessary or not? (Using EIA checklists can be useful)

To respond the above hypothesis, Ch-square test was used. The results are shown in the following table.

Table 3. Chi-square test

\begin{tabular}{cc}
\hline Number & 51 \\
\hline Ch-square & $55.083 \mathrm{a}$ \\
\hline Degree of freedom & 1 \\
\hline Sig. & 0.000 \\
\hline
\end{tabular}

As shown in Table 3, there is a significance difference between comments on formulating EIA checklist among the items. In other words, most of the respondents selected the alternative "Yes".

Table 4. The frequency of selecting "necessity" based on the questionnaire items

\begin{tabular}{ccc}
\hline \multirow{2}{*}{ Checklist is necessary or not necessary } & \multicolumn{2}{c}{ Total } \\
\cline { 2 - 3 } & Frequency & Percentage \\
\hline No & 829 & 41.7 \\
Yes & 1160 & 58.3 \\
Total & 1989 & 100.0 \\
\hline
\end{tabular}

- Investigating the quality of the employed checklist

- Investigating the reliability of the checklist through test-retest method

Table 5. The checklist reliability using test-retest

\begin{tabular}{cccc}
\hline & \multicolumn{3}{c}{ Reliability using test-retest in a 2-week interval } \\
\cline { 2 - 4 } & Correlation coefficient & Number & Sig. \\
\hline Checklist & 0.72 & 51 & 0 \\
\hline
\end{tabular}

As shown in Table 5, the reliability of the checklist using test-retest method after 2 weeks was obtained 0.72 . This value has been significant at error level less than $0.01(\mathrm{p}<0.05)$. Therefore, it can be stated that the checklist has a good level of reliability.

- Investigating the questionnaire's reliability using Cronbach's alpha

Table 6 shows the results of investigating the questionnaire's reliability using Cronbach's alpha.

Table 6. The questionnaire's reliability using Cronbach's alpha

\begin{tabular}{lcc}
\hline & \multicolumn{2}{c}{ Reliability } \\
\cline { 2 - 3 } & Alpha & Number of items \\
\hline Checklist & 0.816 & 105 \\
\hline
\end{tabular}

According to Table 6 , the value of Cronbachs alpha was obtained 0.81 , indicating a good level of reliability of the checklist.

- Execution and Final Control of the Checklist 
Table 7 shows the results obtained by Friedman test to compare the ranked mean of the responses and the final control of the checklist.

Table 7. Friedman test results

\begin{tabular}{cc}
\hline Number & 51 \\
\hline Chi-square & 798.617 \\
\hline Degree of freedom & 38 \\
\hline Sig. & 0.000 \\
\hline
\end{tabular}

As shown in table 7, there is a significant difference among the comments on formulating EIA checklist. In other words, there is a significant difference between responding mean of each item such that the respondents need planning and scenario by agreeing on motivational packages during executing the checklist for individuals involved in the project. Such that, the highest ranked mean belongs to formulating checklist and public benefits have been considered in environmental assessment perspective. EIA review studies have been conducted in details and provided reports have been sent to confirm environment conservation organization.

\section{The first research hypothesis: using EIA checklists can be helpful.}

The Normal distribution of the variable of formulation and assessment. As observed, out of 51 responses, the mean of 65.18 has been obtained, indicating an acceptable normal distribution for the questionnaire. In fact, high dispersion of responses below the curve indicates normal distribution of data. Investigating all the items in formulation and assessment part, it was observed that most of them are averagely and highly important (given to the type of project to which the respondents responded). Higher ranked mean indicates that this item should be mentioned in that certain project.

Chi-square was used to test the above hypothesis. Considering the frequency of the responses, it was observed that the chi-square results are significant at the level less than 0.05 . In other words, the first research hypothesis was confirmed. Considering the observed frequency ( 829 No and 1160 Yes), it can be stated that there is a need of providing checklist to assess environmental impacts. As the causes of confirming the above mentioned hypothesis, it can be referred to the need of assessment and best suggestion for decision making based on technological and economic factors consistent with social and environmental factors, determining actions decreasing effects in project planning process appropriate with probable damages due to project execution, predicting any important, lasting and irrevocable environmental consequence, identifying environmental benefit and cost for community, using public views in decision making process and decreasing dissatisfactions about a project execution, increasing cooperation levels between state and non-state organizations, increasing awareness of people, officials and policy makers about environmental effects of a project, and increasing credit in global community.

\section{The second hypothesis: investigating the quality of the checklist and the type of project}

To investigate the quality of the designed questionnaire, its reliability and validity was evaluated. To evaluate the face validity of the questionnaire, the opinions of 5 experts were asked and after adding and omitting some items, the final questionnaire was formulated. The reliability of the questionnaire was also evaluated and the correlation coefficient of 0.72 was obtained. At the error level of 0.01 , the hypothesis was confirmed.

Then, the questionnaire was distributed among the respondents and the reliability was evaluated using Cronbach's alpha. Then, after 2 weeks, the questionnaire was again distributed. The correlation results of two sets of distribution indicated a good level of reliability. Given to the reliability and validity evaluation reports, it can be confirmed that the questionnaire has a good quality.

\section{The third hypothesis: the way of execution and final control of the checklist}

Ranked mean indicates accumulative agreement on an item. In other words, it shows the importance of designed item. When the respondent agree on the designed items, those items are appropriate to be embedded in the checklist. Although investigating other questions specifies that some questions have lower ranked mean most of the item have a high importance, indicating selection and application of the provided questionnaire and checklist.

To investigate the above mentioned hypothesis, Friedman test was used to compare ranked mean of items and the final control of the checklist. According to the Friedman test results, there is a significant difference among the comments on formulating EIA checklist. In other words, there is a significant difference between responding mean of each item such that the respondents need planning and scenario by agreeing on motivational packages during executing the checklist for individuals involved in the project. Such that, the highest ranked mean belongs to formulating checklist and public benefits have been considered in environmental assessment perspective. EIA review 
studies have been conducted in details and provided reports have been sent to confirm environment conservation organization. According to the respondents' beliefs and ranking the final effective and non-effective factors, the final checklist was formulated and executed. it is highly important to present inspection checklists at the end of EIA reports and reviewing them in various stages of project execution and checking with EIA regulation to execute project or conditionally agree or disagree with design execution during early studies (zero phase) or presenting appropriate strategy to prevent serious damages to environment and its related issues during project execution. All these factors play a key role to prevent delay to Construction Projects operation.

\section{Conclusion}

According to the aforementioned, the final checklist included items related to physical and chemical environments, biological environment, environmental pollutions, and economic-social and cultural environment. The present project aimed at revealing the necessity of presenting EIA in initial studies to prevent delay in Construction Projects operation. Also, with respect to the necessity of checklist, the quality of the designed checklist was investigated, executed and controlled. Each of the research hypotheses were separately stated and then tested. In addition, providing environmental assessment report in study phase caused the creation of a comprehensive view of Construction Project generalities and contribute employers to select the best alternative to execute, conditionally accept (for presenting appropriate environmental strategy) or reject it. Ultimately, it should be noted that the provided checklist cannot be the best provided checklist; however, it can be used a start to execute EIA reports in Construction Projects. With the database containing the life cycle environmental profile of various types of commonly used building materials and energy developed by research team previously, and following the EIA steps, scope definition, inventory analysis and impacts analysis, only the environmental impact related to a construction process, rather than the building that the construction process is intended to deliver, can be identified and calculated. This method provides contractors with a pre-construction decision-making tool to make environmentally friendly construction plans.

\section{References}

[1] Zheng, Lina, Baoxiu Zhao, Hong Wang, and Hengming Liu. "Environmental Risk Identification of Port Construction Project." Procedia Environmental Sciences 10 (2011): 2783-2787. doi:10.1016/j.proenv.2011.09.431.

[2] Miladi Rad, Kaveh, and O. Aminoroayaie Yamini. "The Importance and Use of Risk Management in Various Stages of Construction Projects Life Cycle (PLC).” Modern Applied Science 11, no. 1 (October 5, 2016): 48. doi:10.5539/mas.v11n1p48.

[3] Sarmah, Purbashree, and Arvind K. Nema. "Fuzzy Logic Based Performance Evaluation of EIA Reports for Hydroelectric Projects.” Water Science and Technology Library (December 30, 2017): 153-165. doi:10.1007/978-981-10-5792-2_13.

[4] Li, Fachao, and Li Wang. "Generalized Expected Value Model for Stochastic Programming and Its Application in Transportation Problems." 2009 First International Conference on Information Science and Engineering (2009). doi:10.1109/icise.2009.621.

[5] Arbter, Kersten. "Sustainability Impact Assessment and Strategic Environmental Assessment." OECD Sustainable Development Studies (June 11, 2008): 35-40. doi:10.1787/9789264047266-4-en.

[6] Pourrostam, Towhid, and Amiruddin Ismail. "Causes and Effects of Delay in Iranian Construction Projects." International Journal of Engineering and Technology 4, no. 5 (2012): 598-601. doi:10.7763/ijet.2012.v4.441.

[7] HODGSON, E C. "MARINE AIRPORT FACILITIES FOR CIVIL FLYING BOATS. AIRPORT ENGINEERING DIVISION." The Institution of Civil Engineers Engineering Division Papers 5, no. 20 (January 1947): 3-17. doi:10.1680/idivp.1947.13091.

[8] Chan, Daniel WM, and Mohan M. Kumaraswamy. "Compressing construction durations: lessons learned from Hong Kong building projects." International Journal of Project Management 20, no. 1 (2002): 23-35.

[9] Odeh, A. M., and Battaineh, T. H. (2002). 'Causes of construction delay: traditional contracts” International Journal of Project Management, 20; 67-73.

[10] Sonuga, Femi, Obi Aliboh, and David Oloke. "Particular Barriers and Issues Associated with Projects in a Developing and Emerging Economy. Case Study of Some Abandoned Water and Irrigation Projects in Nigeria." International Journal of Project Management 20, no. 8 (November 2002): 611-616. doi:10.1016/s0263-7863(02)00029-7.

[11] Frimpong, Yaw, Jacob Oluwoye, and Lynn Crawford. "Causes of Delay and Cost Overruns in Construction of Groundwater Projects in a Developing Countries; Ghana as a Case Study." International Journal of Project Management 21, no. 5 (July 2003 ): 321-326. doi:10.1016/s0263-7863(02)00055-8.

[12] Diliman, Quezon City. "Traffic impact assessment for sustainable traffic management and transportation planning in urban areas." In Proceedings of the Eastern Asia Society for Transportation Studies, vol. 5, pp. 2342-2351. 2005.

[13] Htun, Nay. "EIA AND SUSTAINABLE DEVELOPMENT." Impact Assessment 8, no. 1-2 (June 1990): 15-23. 
doi:10.1080/07349165.1990.9726025.

[14] “Project Execution.” Project Management Case Studies (April 21, 2017): 211-308. doi:10.1002/9781119389040.ch9.

[15] Sommer, Hans. "Fundamentals of Project Execution." Project Management for Building Construction (December 12, 2009): 2-15. doi:10.1007/978-3-642-10874-7_1.

[16] Li, Xiaodong, Yimin Zhu, and Zhihui Zhang. "An LCA-Based Environmental Impact Assessment Model for Construction Processes.” Building and Environment 45, no. 3 (March 2010): 766-775. doi:10.1016/j.buildenv.2009.08.010. 